\title{
Rol de las células mioepiteliales en el desarrollo de tumores complejos y mixtos de la glándula mamaria canina
}

\author{
Rosciani, A.S. ${ }^{1}$; Merlo, W.A.'; Insfrán, R.M..; Benítez, J.S. ${ }^{1}$; Ortega, H.H. ${ }^{2}$ \\ ${ }^{1}$ Servicio de Diagnóstico Histopatológico y Citológico, Facultad de Ciencias Veterinarias, UNNE, \\ Sargento Cabral 2139, Corrientes (3400), Argentina, Tel. 03783-425753. ${ }^{2}$ Cát. Biología Celular, \\ Fac. Cs. Veterinarias. UNL. E-mail: arosciani@vet.unne.edu.ar.
}

\begin{abstract}
Resumen
Rosciani, A.S.; Merlo, W.A.; Insfrán, R.M.; Benítez, J.S.; Ortega, H.H.: Rol de las células mioepiteliales en el desarrollo de tumores complejos y mixtos de la glándula mamaria canina. Rev. vet. 21: 1, 19-22, 2010. Las células mioepieliales (CME) proliferan en los tumores de mama complejos y mixtos de la especie canina, por lo cual es importante caracterizarlas y probar su transformación en tejido mixoide, cartílago y hueso. En tal sentido se ha descrito que distintos tipos de CME al proliferar sufren transformaciones fenotípicas (hipertróficas, fusiformes, estrelladas, redondas, condroblastos) y capacidad de generar abundante matriz intercelular de características dispares. El objetivo de esta comunicación fue presentar los resultados obtenidos con la doble inmunomarcación del antígeno nuclear de proliferación celular (PCNA) y alfa actina de músculo liso (AA), lo que ha permitido evidenciar las CME en proliferación. Asimismo, reportar la posibilidad de identificar morfológicamente distintas variedades de estas células en preparados coloreados con hematoxilina y eosina (HyE). Se estudiaron 54 tumores mamarios caninos diagnosticados como carcinoma complejo (CC), carcinoma simple (CS) y carcinoma en tumor mixto benigno (CTM). Se realizó el reconocimiento de las cinco variedades de CME descriptas por otros autores en los cortes coloreados con HyE. En los CC se observaron todas las variedades de CME excepto condroblastos y/u osteocitos, que sí se presentaron en los CTM. Los CS mostraron la presencia de CME fusiformes e hipertróficas. Se observó marcación positiva a AA en los citoplasmas de la totalidad de las células de tipos fusiforme e hipertróficas. Hubo leve marcación en menos del 50\% de las células estrelladas. No se observaron células redondas marcadas y sólo en dos oportunidades hubo positividad muy leve en condroblastos/osteocitos. Los recuentos de núcleos de las CME positivas a PCNA fueron superiores en CC $(17,33)$ y CTM $(15,67)$ sobre CS $(12,56)$, aunque las diferencias fueron no significativas. Se corrobora que en los carcinomas en tumor mixto benigno y complejo las CME proliferan, se transforman y dan origen a zonas de tejido con aspecto fibroso, mixoide y condroide.
\end{abstract}

Palabras clave: perra, glándula mamaria, células mioepiteliales, carcinomas en tumores mixto y complejo.

\begin{abstract}
Rosciani, A.S.; Merlo, W.A.; Insfrán, R.M.; Benítez, J.S.; Ortega, H.H.: Myoepithelial cells' role in the development of complex and mixed tumors in canine mammary gland. Rev. vet. 21: 1, 19-22, 2010. Myoepithelial cells (MEC) proliferate in complex and mixed canine mammary gland tumors. They usually transform into cells from myxoid, chondroid and bone tissues. Different attempts to characterize and make them evident have been made, by using specific markers. Myoepithelial cells suffer phenotypic transformations during proliferation, and different types of such transformations have been described: fusiform, hypertrophic, stellate and rounded myoepithelial cells and chondroblasts. The purpose of this assay is to present the results from the proliferation cells' nuclear antigen (PCNA) and alpha smooth muscle actin (AA) double immunohistochemical technique, which revealed CME proliferation. In addition, to report the description of morphologically identified MEC's varieties on hematoxilin and eosine slides. Fifty four canine mammary tumours diagnosed as simple (SC) and complex carcinomas (CC), and carcinomas in mixed benign tumours (CMT), were studied. The five MEC's varieties (previously described by other authors, were recognized. All types, except for chondroblasts and or osteocytes, were observed in $\mathrm{CC}$, whereas all of them were seen in CTM. SC showed the presence of fusiform and hypertrophic MEC. Positive AA cytoplasmic staining pattern was seen in the all of fusiform and hypertrophic
\end{abstract}

Recibido: 7 mayo 2010 / Aceptado: 14 junio 2010 


\begin{abstract}
MEC. Less than $50 \%$ of stellate MEC was weakly reactive. No positive rounded MEC were observed. Chondroblasts and osteocytes were observed with a weak stain only in two occasions. CC $(17,33)$ and CTM $(15,67)$ showed the highest PCNA reactive MEC's nucleus counts over SC $(12,56)$, although no significant statistics differences were found. These findings are in agreement with the current presumption that MEC proliferate, transform and give rise to different tissues such as fibrous, myxoid and chondroid.
\end{abstract}

Key words: bitch, mammary gland, myoepithelial cells, carcinomas in mixed and complex tumours.

\section{INTRODUCCIÓN}

La especie canina se caracteriza por la ocurrencia de tumores de mama complejos y mixtos ${ }^{13}$, llamativos por su frecuencia y su heterogeneidad histomorfológica 4, 14 . Existen varias hipótesis sobre la histogénesis de estos tumores, a saber: un origen común a partir de una célula madre ${ }^{9,10}$, metaplasia a partir de células epiteliales ${ }^{7}$, metaplasia del tejido conectivo ${ }^{16} \mathrm{y}$ finalmente la teoría que ha dado mayores evidencias de ser probable: metaplasia a partir de las células mioepiteliales (CME) ${ }^{2}$. Dentro de esta última concepción, se han realizado diversos trabajos intentando caracterizar a las CME (que aparentemente proliferan en tales neoplasias) y probar su transformación en tejido mixoide, cartílago y hueso.

Para evidenciar las CME se han empleado diversos marcadores tales como alfa actina de músculo liso, calponina, caldesmona, desmina, miosina de cadena pesada de músculo liso, proteína fibrilar glial ácida, S-100, citoqueratina 14 y vimentina ${ }^{2,5,6,15,16}$. Basándose en la identificación por medio de calponina, se describen distintos tipos de CME que van sufriendo transformaciones fenotípicas a medida que proliferan: hipertróficas, fusiformes, estrelladas y redondas, las cuales pueden además generar abundante matriz intercelular de características dispares ${ }^{3,17}$.

Esta comunicación tiene como objetivo presentar los resultados obtenidos con la doble inmunomarcación del antígeno nuclear de proliferación celular (PCNA, clon PC10 de Novocastra) y alfa actina de músculo liso (AA, clon sm1, de Novocastra), los cuales permiten revelar las CME en proliferación. Asimismo, reportar la posibilidad de identificar morfológicamente en preparados coloreados con hematoxilina y eosina (HyE) las distintas variedades de estas células.

\section{MATERIAL Y MÉTODOS}

Se estudiaron 54 tumores mamarios caninos diagnosticados como carcinoma complejo (CC), carcinoma simple (CS) y carcinoma en tumor mixto benigno (CTM), de acuerdo a la actual clasificación de la OMS ${ }^{13}$. Las piezas quirúrgicas fueron procesadas de acuerdo con la técnica histológica clásica y coloreadas con HyE.
Se practicó la doble inmunomarcación de cortes para mostrar AA de músculo liso en los citoplasmas de las células mioepiteliales y PCNA, proteína asociada a la polimerasa delta que se hace visible en los núcleos de las células en división, desde el estadío G1 hasta el inicio de la mitosis. Se empleó el kit de Biotina-estreptavidina-peroxidasa ("supersensitive immunodetection system", LP000-UL, Biogenex, CA, USA). Se siguieron los lineamientos generales de los laboratorios proveedores de los distintos anticuerpos. Se realizó inactivación de la peroxidasa endógena y bloqueo con suero normal de cabra (ya que el anticuerpo secundario empleado fue desarrollado en esta especie).

Finalmente los distintos cortes se incubaron con el anticuerpo primario PCNA: anticuerpos primarios monoclonales de ratón, clon PC10 de Novocastra, con incubación de 40 min a temperatura ambiente. Se realizó primero esta técnica con revelado de DAB y posteriormente se inició la marcación del segundo antígeno AA: anticuerpo de ratón clon sm1, de laboratorios Novocastra, durante 30 a $60 \mathrm{~min}$, revelado por medio de estreptavidina- peroxidasa (HK 330 Biogenex) y solución AEC (HK139 de Biogenex).

\section{RESULTADOS}

Se realizó el reconocimiento de las cinco variedades descriptas en los cortes coloreados con HyE. En los CC se observaron todas las variedades de CME (fusiformes, hipertróficas, estrelladas y redondeadas) excepto condroblastos y/u osteocitos, que sí se presentaron en los CTM (Figuras 1 a 3). Los CS mostraron la presencia de CME fusiformes e hipertróficas, formando una hilera simple o doble como máximo, sobre la membrana basal.

Las CME, aumentadas en número, en los tres tipos tumorales estudiados manifestaron positividad a AA. Las variedades morfológicas de CME fusiformes e hipertróficas mostraron mayor intensidad de inmunomarcación en la totalidad de las células (Figura 4). Las CME con cambios de aspecto más marcados como las variedades estrelladas, redondas y condrocitos, evidenciaron menos positividad. El $50 \%$ de las células estrelladas fue levemente positivo, los condrocitos se marcaron escasamente y las CME redondas no lo hicieron.

En cuanto a los recuentos de núcleos de los distintos tipos de CME positivos a PCNA (Figura 4), se 
observaron promedios superiores en los CC $(17,33)$ y CTM $(15,67)$ sobre los CS $(12,56)$, aunque entre las variedades no se encontraron diferencias estadísticamente significativas.

\section{DISCUSIÓN}

En los preparados coloreados con HyE fue posible identificar las distintas variedades de CME descriptas previamente en base a la inmunomarcación con calponina ${ }^{3}$, tanto en los carcinomas en tumor mixto como en los carcinomas complejos. Inclusive, se observó proliferación e hipertrofia de estas células en los carcinomas simples.

Se observó marcación positiva a AA de los citoplasmas de la totalidad de las CME de los tipos fusiformes e hipertróficos. Hubo leve marcación en menos del 50\% de las células de variedad estrellada. No se observaron células redondas marcadas y sólo en dos oportunidades hubo positividad muy leve en condroblastos y osteocitos. Otros autores refieren, también en neoplasias ma-



Figura 1. Carcinoma complejo. A la derecha de la imagen se observan células carcinomatosas formando estructuras tubulares, células mioepiteliales fusiformes rodeando estas estructuras (flecha) y en el centro células mioepiteliales hipertróficas (cabezas de flechas). HyE, 400x.

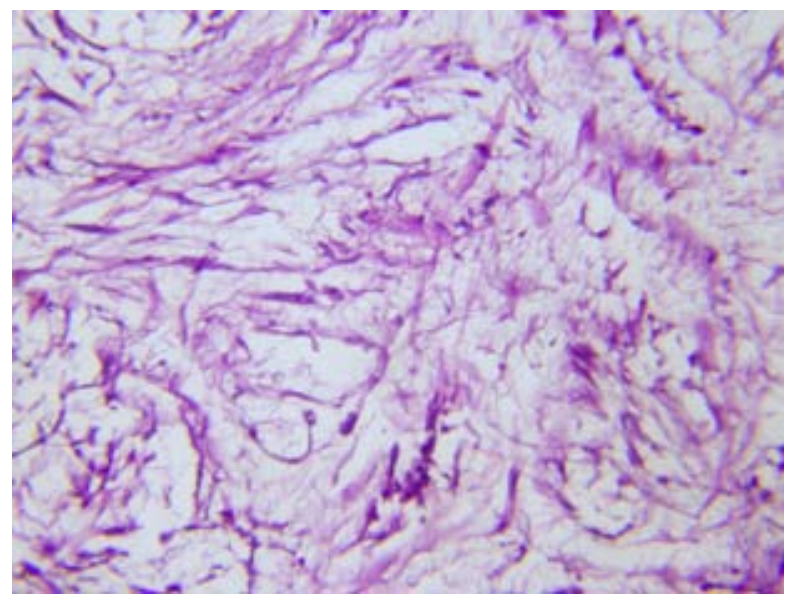

Figura 2. Carcinoma complejo. Células mioepiteliales estrelladas, en un área de tejido mixoide. HyE, 200x. marias caninas, pérdida de inmunomarcación de AA en las CME de áreas con material amorfo mucinoso, cartilaginoso u osificado ${ }^{12}$. Por su parte, otro grupo de investigadores explica que las células mioepiteliales proliferantes de tumores mixtos de glándula mamaria canina van perdiendo expresión de marcadores específicos como AA, mientras se va acentuando la expresión de beta-tubulina de clase II y producen colágeno específico de cartílago ${ }^{1}$.

El origen de las distintas variedades de neoplasias mamarias en la especie canina ha sido ampliamente discutido $^{2,5,7-11}$. Se considera que los resultados aquí obtenidos, tanto la identificación de las distintas variedades de CME con HyE, así como su inmunomarcación con AA y los recuentos de núcleos de CME en proliferación se encuadrarían en la hipótesis más aceptada actualmente, que establece que las células mioepiteliales en los carcinomas complejos y carcinomas tumor mixto proliferan, se transforman y dan origen a zonas de tejido de aspecto fibroso, mixoide o condroide.

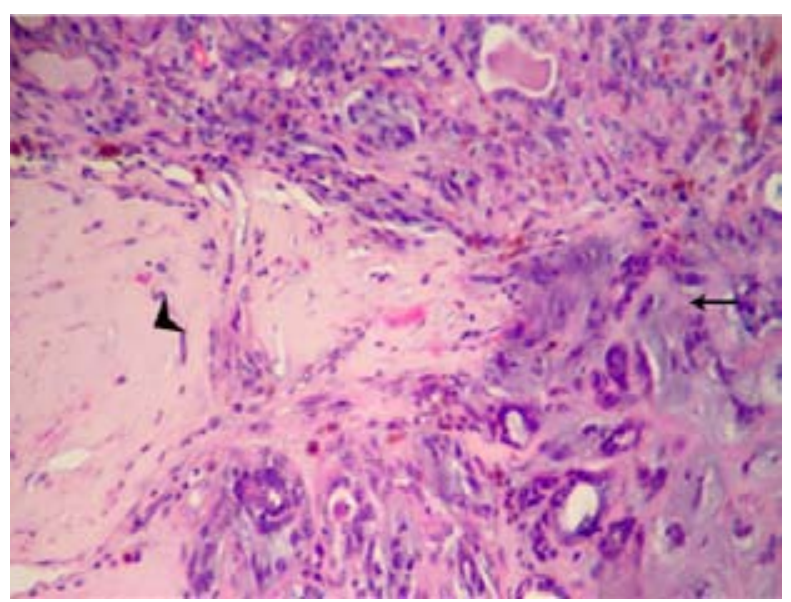

Figura 3. Carcinoma en tumor mixto benigno. Células carcinomatosas en distribución difusa y tubular, entre células mioepiteliales, áreas de cartílago (flecha) y sustancia osteoide (cabeza de flecha). Grado tumoral I. HyE, 100x.

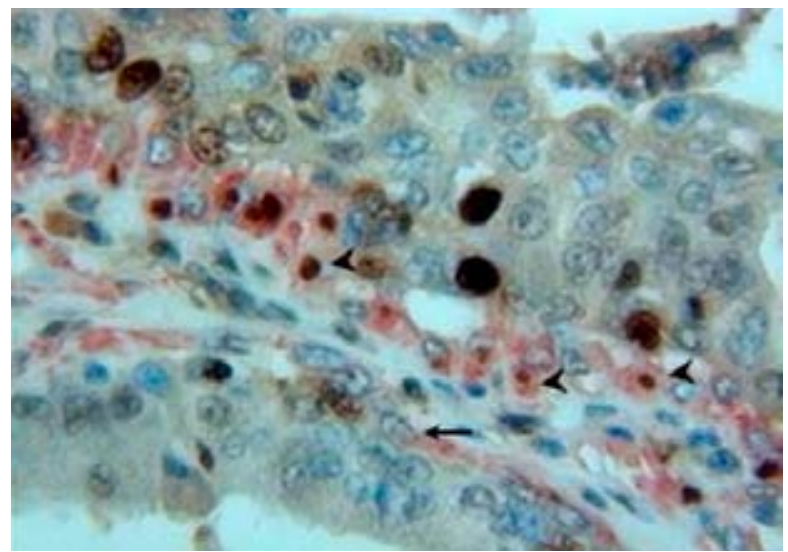

Figura 4. CME fusiformes (flecha) e hipertróficas (cabezas de flechas) de coloración eosinófila, postivas a AA y núcleos marrones positivos a PCNA. Doble inmunomarcación, 400x. 


\section{REFERENCIAS}

1. Arai K, Nakano H, Shibutani M, Naoi M, Matsuda H. 2003. Expression of class II beta tubulin by proliferative myoepithelial cells in canine mammary mixed tumors. Vet Pathol 40: 670-676.

2. Destexhe E, Lespagnard L, Degeyter M, Heymann R, Coignoul F. 1993. Immunohistochemical identification of myoepithelial, epithelial and connective tissue cells in canine mammary tumors. Vet Pathol 30: 146-154.

3. Espinosa A, Millán MY, Ordás J, Carrasco L, Reymundo C, Martín J. 2002. Immunolocalization of the smooth muscle-specific protein calponin in complex and mixed tumors of the mammary gland of the dog: assessment of the morphogenetic role of the myoepithelium. Vet Pathol 39: 247-256.

4. Foster R. 2007. Female reproductive system. In: Pathologic basis of veterinary disease (McGavin MD, Zachary JF Ed.), $4^{\text {th }}$ ed, Mosby, Saint Louis, p. 1263-1315.

5. Gama A, Alves A, Gartner F, Schmitt F. 2003. P63: a novel myoepithelial cell marker in canine mammary tissues. Vet Pathol 40: 412-420.

6. Gartner F, Geraldes M, Cassali G, Rema A, Schmitt F. 1999. DNA measurement and immunohistochemical characterization of epithelial and mesenchymal cells in canine mixed tumours: putative evidence for a common histogenesis. Vet $J$ 158: 39-47.

7. Griffey SM, Madewell BR, Dairkee SH, Hunt JE, Naydan DK, Higgins RJ. 1993. Immunohistochemical reactivity of basal and luminal epithelium-specific cytokeratin antibodies within normal and neoplastic canine mammary glands. Vet Pathol 30: 155-161.

8. Hellmén E, Lindgren A. 1989. The expression of intermediate filaments in canine mammary glands and their tumors. Vet Pathol 26: 420-428.

9. Hellmén E. 1992. Characterization of four in vitro established canine mammary carcinomas and one atypical benign mixed tumor cell line. In Vitro Cell Dev Biol 28A: 309-319.
10. Hellmén E, Bergstrom R, Holmberg L, Spangberg IB, Hannson K, Lindgren A. 1993. Prognostic factors in canine mammary tumors: a multivariate study of 202 consecutive cases. Vet Pathol 30: 20-27.

11. Hellmén E, Maller M, Blankestein MA, Anderson L, Westermark B. 2000. Expression of different phenotypes in cell lines from canine mammary spindle-cell tumours and osteosarcomas indicating a pluripotent mammary stem cell origin. Breast Cancer Res Treat 61: 197-210.

12. Milli ÜH, Haziroglu R, Aydin Y, Gülbahar MY. 2000. Immunohistochemical localization of cytokeratin, vimentin an alpha smooth muscle actin, micro and intermediate filaments in canine mammary tumors. Turkish J Vet Anim Sci 24: 81-92.

13. Misdorp W, Else RW, Hellmén E, Lipscomb TP. 1999. Histological classification of mammary tumors of the dog and the cat, $2^{\text {nd }}$ series, Publ. Armed Forces Institute of Pathology with The World Health Organization, Washington, vol. 7.

14. Moulton JE. 1990. Tumors of the mammary gland. En: Tumors in domestic animals (Moulton JE ed.), $3^{\text {rd }}$ ed., California Press, Berkeley, p. 518-553.

15. Vos JH, Van den Ingh TS, Misdorp W, Molenbeek RF, Van Mil FN, Rutterman GR, Ivanyi D, Ramackers FC. 1993. Immunohistochemistry with keratin, vimentin, desmin and alfa smooth muscle actin monoclonal antibodies in canine mammary gland: benign mammary tumors and duct ectasias. Vet $Q$ 14: 89-95.

16. Vos JH, Van den Ingh TS, Misdorp W, Molenbeek RF, Van Mil FN, Rutterman GR, Ivanyi D, Ramackers FC. 1993. Immunohistochemistry with keratin, vimentin, desmin and alfa smooth muscle actin monoclonal antibodies in canine mammary gland: malignant mammary tumors. Vet $Q$ 14: 96-102.

17. Wensman H, Flama V, Pejler G, Hellmén E. 2008. Plasticity of cloned canine mammary spindle cell tumor, osteosarcoma and carcinoma cells. Vet $\mathrm{Pa}$ thol 45: 803-815. 